DOI 10.37882/2223-2974.2021.02.21

\title{
ЕВРАЗИЙСКАЯ КОНЦЕПЦИЯ ПРАВА СОБСТВЕННОСТИ: ИСТОКИ И СОВРЕМЕННОЕ ЗНАЧЕНИЕ ${ }^{1}$
}

\section{EURASIAN CONCEPT OF OWNERSHIP: ORIGINS AND MODERN VALUE}

A. Serebryakov

Summary: Currently, the institution of property law is being challenged. In such conditions, it is important to consider not only the historical experience of legal regulation of property relations, but also to rethink the achievements of Russian philosophical and legal thought. The study contains an analysis of the Eurasian concept of property rights set out in the works of N.N. Alekseev. It seems that the provisions of the concept under consideration can be used to improve domestic civil legislation on property rights.

Keywords: Eurasianism; N.N. Alekseev; property rights; public-private economy system; real right; own.
Серебряков Андрей Александрович

старший преподаватель, Алтайский государственный университет (2. Барнаул) goodwrong@gmail.com

Аннотация: В настоящее время институт права собственности подвергается новым вызовам. В подобных условиях важным представляется учитывать не только исторический опыт правового регулирования отношений собственности, но переосмыслить достижения отечественной философско-правовой мысли. Исследование содержит анализ евразийской концепции права собственности, изложенной в трудах Алексеева Н.Н. Представляется, что положения рассматриваемой концепции могут быть использованы в целях совершенствования отечественного гражданского законодательства 0 праве собственности.

Ключевые слова: евразийство; Н.Н. Алексеев; право собственности; система государственно-частного хозяйства; вещное право; собственность.

правовой регламентации общественных отношений, в частности, по вопросам права собственности как одного из центральных столпов гражданского права.

В отечественной дореволюционной правовой доктрине собственность и право собственности рассматривались как одно из выдающихся достижений человечества. Покровский И.А. отмечал: «Появление вещных прав, т.е. построение отношений к вещам по типу субъективных индивидуальных прав, представляет в истории всякого общества огромный шаг вперед...Оно было одним из первых требований развивающейся личности, и создание его явилось в реальной исторической обстановке прошлого важнейшей победой для этой последней. Это относится прежде всего к основному из вещных прав, составляющему краеугольный камень всей нынешней народнохозяйственной жизни, - к праву собственности» [5].

Мейер Д.И. подчеркивал значение права собственности следующим образом: «В области юридических отношений право собственности является необходимостью и в гражданском праве занимает первое место. Были и есть писатели, утверждающие, что в некоторых обществах юридический быт устанавливается без права собственности. Но это несправедливо: право собственследию отечественной философско-правовой мысли, предлагающей несколько иной подход к осмыслению

Исследование выполнено при финансовой поддержке фонда грантов Президента РФ для молодых российских ученых - кандидатов наук, проект № МК-483.2020.6 «Евразийская альтернатива государственно-правового развития России: генезис, содержание, современное прочтение». 
ности, иногда сокрыто, существует в грубых формах, но тем не менее оно всегда и везде существует» [6].

Вместе с тем, анализ источников позволяет сделать вывод, что право собственности до революции рассматривалось, прежде всего, через призму достижений европейской правовой мысли. Так, Покровский И.А., раскрывая вопрос о развитии правового регулирования отношений собственности на примере европейских стран, с сожалением отмечает: «Наше русское право и в этом отношении стоит далеко позади» [5].

Стоит также отметить, что хотя отечественными юристами того времени вопрос об упразднении института частной собственности серьезно не рассматривался, некоторые авторы допускали необходимость учета общественных интересов. В частности, Покровский И.А. соглашался с тем, что «принцип частной собственности может при известных условиях вступать в резкие конфликты с интересами общенародными. Тогда по необходимости приходится вспоминать о том, что недвижимость есть не только частное, но и национальное достояние» [5]. В то же время он полагал, что учения о социальной функции собственности (в частности, учение Л. Дюги) подрывают стимулирующую функцию собственности, разрушают сложившийся порядок народного хозяйства.

Развитие социалистических идей и последующие социально-экономические потрясения начала 20 века неизбежно поставили вопрос о пересмотре сложившейся отечественной правовой системы. В результате, в первые же годы советской власти происходит отмена частной собственности на землю (Декрет о земле 1917 г.). Однако при этом полной отмены института собственности все же не произошло. Уже в 1922 г. Гражданский кодекс РСФСР закрепил в ст. 52 государственную, кооперативную и частную. При этом в советской юридической литературе постулировалось, что право государственной социалистической собственности со временем отомрет. Останется только обобществленная собственность, «... государственная и кооперативная собственность сольются, а другого права собственности уже не будет, раз не будет больше классов» [7, с. 26].

Казалось бы сложившиеся подходы к институту собственности и праву собственности, буржуазный и социалистический, являются безальтернативными и остается только выбрать один из них в качестве основы развития общества. Однако в рамках политико-правового учения евразийства были сформулированы основы для развития иного подхода к пониманию права собственности.

Основоположником евразийской концепции права собственности и фактически её единственным представителем является Алексеев Н.Н.
Потребность высказать собственную точку зрения о сущности права собственности возникла у Алексеева Н.Н. после того, как он разочаровался в идеях капитализма и социализма [8, с. 88]. В своей работе «Собственность и социализм : опыт обоснования социально-экономической программы евразийства» автор предпринял попытку изложить альтернативный подход к пониманию права собственности и института частной собственности в духе идей евразийства [9].

Алексеев Н.Н. тонко подмечает две крайности. С одной стороны, при капиталистическом укладе происходит идеализация института частной собственности, признание её единственной движущей силой и главным инструментом достижения социального равновесия. С другой стороны, в рамках социалистических воззрений на частную собственность последняя всячески отрицается, как утратившая всякую ценность. Тем не менее Алексеев Н.Н. усматривает и взаимосвязь между этими полярными точками зрения: «...все современное социальное движение и связанный с ним красный призрак социальной революции являются неизбежной обратной стороной общественного порядка, построенного на исключительном господстве принципа частной собственности» [10, С. 187]. Недостатки каждого подхода дестабилизируют общественные отношения, создают угрозы устойчивому развитию.

По мнению Алексеева Н.Н. проблему собственности стоит рассматривать не только с юридической, исторической или политической точек зрения, но и с философских позиций. Именно в этом заключается суть евразийской концепции права собственности.

К началу 20 века наиболее распространенное определение права собственности гласило: право собственности - это неограниченное и исключительное господство лица над вещью [11, С. 259]. В советский юридической науке при рассмотрении вопроса о понятии права собственности акцент смешался в сторону того, право собственности опосредует отношение в обществе между людьми и классами по поводу вещей [12, С. 293]. Современные юридическая наука определяет субъективное право собственности как закрепленную законом возможность лица по своему усмотрению владеть, пользоваться и распоряжаться принадлежащим ему имуществом, одновременно принимая на себя бремя и риск его содержания [13, С. 43]. Общей чертой приведенных воззрений на право собственности является то, что данное право существует в силу его признания обществом и нормативного закрепления.

Вместе с тем, Алексеев Н.Н. полагал, что право собственности имеет объективные начала, в том смысле, что существуют доправовые основы собственности, отражающие её признаки и отличия, независимо от того 
имеют ли они формальное закрепление в нормативных правовых актах. Исследуя данную гипотезу Алексеев Н.Н. предпринял попытку установить доправовое строение собственности, проанализировав четыре правовые категории:

- правовой субъект;

- правовой объект;

- правовое содержание;

- правовое отношение.

Рассуждая о субъектах права собственности Алексеев Н.Н. приходит к выводу, что таковым может быть «не личность вообще, но та личность, которая обладает телесной природой, следовательно, субъектом права может быть физический индивидуум» [10, С. 193]. В основу такого вывода положен критерий ограниченности, но не только объектов материального мира, но и результатов интеллектуальной деятельности человека, поскольку человек не способен творить бесконечно. Тем не менее, Алексеев Н.Н. не отрицает в качестве субъектов права собственности юридические лица, рассматривая их как многочеловеческие личности, которые «имеют земные нужды, должны производить и потреблять блага, словом, должны, как и отдельные люди, подчиняться всем законам физического бытия» [10, С. 194].

Критерий ограниченности используется Алексеевым Н.Н. также при установлении доправовых начал объекта права собственности. Ограниченность объектов проявляется как в их фактическом недостатке (вещи, определяемые родовыми признаками), так и в их индивидуальном характере или незаменимости (индивидуально-определенные вещи). Следовательно, собственность зиждется на лишении, бедности. Приводя в качестве примера первоначальные способы приобретения собственности (захват (оккупация) и обработка вещи), Алексеев Н.Н. констатирует, что «достаточно ознакомиться с обычным правом русского парода, чтобы убедиться, что захват и труд - таковы были в его убеждении первые титулы собственности» [10, С. 195]. Затраченные или сэкономленные усилия на приобретение объекта собственности представляются реальным основанием собственности, в основе которого покоится принцип траты, труда и сбережения сил. Вместе с тем, Алексеев Н.Н. предостерегает от увлечения концепцией суверенитета личности, поскольку «принадлежности» личности неотчуждаемы, тогда как «принадлежности» в смысле собственности принципиально могут отчуждаться и возможность их отчуждения может быть ограничена, но не отрицаема принципиально [10, С. 197]. Пренебрежение данным подходом может стать причиной ошибочного вывода о возможности отчуждения личности человека.

Весьма интересным представляется предложенный Алексеевым Н.Н. анализ содержания права собственности. Не отрицая такие элементы субъективного права собственности как господство и распоряжение, исследователь предлагает учитывать особенности восприятия вещей человеком и проистекающее из этого отношение к ним. Идеи того, что человек является абсолютным собственником материи, сложившейся в европейской философской традиции, Алексеев Н.Н. противопоставляет евразийский подход, согласно которому человеку «не принадлежит право безусловного присвоения мира» [10, С. 199]. Здесь также важно учитывать характеристику самих отношений, складывающихся по поводу господства и распоряжения собственностью. По мнению Алексеева Н.Н. эти отношения носят властный характер, однако, это власть хозяйская, в которой объекты выступают средством, а не целью. При этом сам процесс хозяйствования является социальным и включает других субъектов помимо собственника. Хозяйской власти противопоставляется власть социального служения, которая не составляет содержания права собственности т.к. преследует высшие цели. Исходя из изложенного, Алексеев Н.Н. определял содержание права собственности как «принадлежащее физическому субъекту право господства и распоряжения такими, встречающимися в природе в ограниченности вещами, которые в порядке ценностной иерархии являются ценностями низшими» $[10$, C. 200].

Рассматривая отношения, возникающие между собственником и другими субъектами, Алексеев Н.Н. соглашается с тем, что они носят абсолютный характер. Однако он предлагает рассматривать собственность не с экономической точки зрения, а как социальное отношение: «Институт собственности предполагает равным образом идею целокупности, в которой нет членов, оторванных и ушедших в себя, в которой каждый является членом некоторого идеального организма. Собственность поэтому не есть индивидуальное отношение лица к вещи или, через посредство этой вещи, к другому определенному лицу...Собственность есть, таким образом, социальное отношение всеобщей природы, обстоятельство которое входит в сущность собственности, но далеко не всегда достигает сознания людей, даже собственностью обладающих» [10, С. 201]. Данный подход Алексеев Н.Н. противопоставляет индивидуалистическим и естественно-правовым концепциям, согласно которым личность собственника имеет главенствующее значение, в то время как социальные связи с другими субъектами уходят на второй план и им не уделяется должного внимания. Алексеев Н.Н. видит установление собственности не в одностороннем акте лица, но в акте всего общества.

Вышеуказанные особенности всецело находят свое отражение в предложенном Алексеевым Н.Н. определении собственности как отношения между людьми, при котором праву собственника на господство и распоряжение над встречающимися в ограниченности и не принадлежащими к высшим ценностям предметами 
соответствует универсальная обязанность других людей терпеть власть собственника и не вмешиваться в ее определенные проявления [10, С. 203].

Сформулированные доправовые основы собственности позволяют прийти к выводу, что без института собственности невозможна хотя бы относительные стабильность и благополучие в условиях перманентной ограниченности благ. Однако в целях обеспечения функционирования нормального общественного порядка, по мнению Алексеева Н.Н., важным является познание «ценности идеалов умеренности и нестяжания» [10, С. 209].

Вышеприведенные основные начала института собственности позволили Алексееву Н.Н. предложить классификацию видов собственности. Всего предложено 4 классификационных критерия [10, С. 210]:

1. субъекты собственности;

2. объекты собственности;

3. содержание действий, связывающих субъект с объектом;

4. характер правоотношений, в которых собственник стоит с другими членами общественного целого.

По критерию «субъекты собственности» выделялись личная собственность и общая собственность (коллективная). Личная собственность принадлежит одному физическому лицу. Примером коллективной собственности является собственность юридических лиц (организованный коллектив), например, акционерных обществ, или собственность нескольких физических лиц (неорганизованный коллектив), например, лица, получившие в наследство дом.

По критерию «объекты собственности» выделены движимые вещи и недвижимость. Но Алексеев Н.Н. более важным полагал деление собственности в рамках данного критерия на собственность на землю; собственность на орудия производства; собственность на потребляемые вещи, что было обусловлено существовавшими в период создания евразийского учения о собственности историческими реалиями.

В соответствии с критерием «содержание действий, связывающих субъект с объектом» было предложено рассматривать абстрактные отношения собственности и конкретные отношения собственности. В первом случае содержание права собственности не зависит от объекта собственности. Наоборот, во втором случае содержание права собственности преобразуется и конкретизируется в зависимости от степени социализации общества путем установления ограничений в отношении отдельных видов собственности.

Согласно критерию «характер правоотношений, в которых собственник стоит с другими членами общественного целого» следует различать безусловную собственность (абсолютную) и ограниченную собственность (относительную). В рамках безусловной собственности право собственности претендует на исключительность, а отношения между собственником и прочими субъектами строится по односторонней модели: управомоченный субъект (собственник) - обязанные субъекты (все прочие). В этом случае согласно Алексееву Н.Н. «ограничения собственности могут быть установлены только в целях ее утверждения» [10, С. 214]. Иной подход реализован в относительной собственности. Здесь право собственности «включает в себя идею границы и потому выносит различные ограничения» [10, С. 214], т.е. утрачивает свою исключительность. Собственника могут связывать различные публично-правовые ограничения, налагающие на него определенные социальные обязанности. Поэтому в данной ситуации следует руководствоваться двусторонней моделью: с одной стороны собственник является управомоченным лицо, с другой стороны он является обязанным по отношению ко всем третьим лицам, в части соблюдения установленных ограничений.

Евразийская концепция права собственности не обходит вниманием вопрос о соотношении частной и публичной собственности. Согласно воззрениям Алексеева Н.Н. основные отличия между публичной собственностью и частной собственностью состоят в следующем. Объекты публичной предназначены для общего пользования, в то время как объекты частной собственности обслуживают личные или групповые интересы. Господство и распоряжение публичной собственностью представляет собой «социальное служение», т.к. совершается для достижения высших целей и ценностей. В то же время господство над предметами частной собственности предполагает проявление хозяйской власти. Публичные собственники по отношению к частным собственникам являются властвующими, но частные собственники по отношению друг к другу являются свободными и равными, тогда как по отношению к публичным собственникам они являются подчиненными. В результате Алексеев Н.Н. приходит к выводу: «Существование частной собственности указывает на существование такого общественного порядка, в котором имеется некоторая принудительная централизованная сфера жизни и наряду с ней другая, децентрализованная сфера, основанная на хозяйственном самоопределении различных индивидуальных или коллективных правовых субъектов, владеющих отдельно или сообща, абсолютно или относительно различными правовыми объектами» [10, С. 217].

В современных исследованиях отмечается вся важность и значение учета политики права при правовом регулировании общественных отношений [15]. В этой связи стоит обратить внимание на тот факт, что Алек- 
сеев Н.Н. уделил внимание оценке института частной собственности не только как правового явления, но рассмотрел его с технико-экономической и нравственной точек зрения. Всесторонний подход позволил Алексееву Н.Н. прийти к выводу о необходимости преобразования содержания института собственности и пересмотра вопроса об отношении субъекта собственности к объектам. В качестве альтернативы капитализму и социализму он предлагает систему государственно-частного хозяйства. В основе этой системы лежит парадигма относительной собственности, когда образуется взаимная связь между правами и обязанностями собственника с одной стороны и правами и обязанностями общества с другой стороны.

Вместе с тем, одного лишь юридического закрепления относительной собственности недостаточно для возведения нового общественного уклада. Алексеев Н.Н. отмечает важность общекультурного содержания жизни субъекта собственности: «преодоление капитализма принципиально возможно только в том случае, когда наряду с законодательством совершится и преобразование идейных предпосылок жизни» [10, С. 265]. Идейная основа для этого содержится в учении евразийства, которое утверждает преобладание духовных начал над материальными.

В качестве следующего элемента системы государственно-частного хозяйства Алексеев Н.Н. называет признание своеобразия объектов собственности, в отношении которых необходимо применять те или иные правовые нормы.

Не менее важным представляется обеспечение возможности различных субъектов получить доступ к средствам производства. Алексеев Н.Н. утверждал: «Орудия производства должны принадлежать, таким образом, и государству, и его частям, и частным обществам, и частным лицам, и трудовым кооперативам или коммунам. Состязание всех их покажет, кто более способен к жизни, и заставит каждого напрягать все возможные усилия для обеспечения своего существования» [10, С. 274].

Таким образом, предложенная Алексеевым Н.Н. система государственно-частного хозяйства представляет собой ядро евразийской концепции права собственности. Ее ключевыми особенностями являются: признание в качестве собственников объективно существующих субъектов, реально участвующих в общественной и экономической жизни, а также поощрение и создание благоприятных условий для развития разнообразных собственников; установление дифференцированных режимов оборота отдельных видов благ, исходя из общего критерия ограниченности объектов собственности; закрепление ограничений в отношении отдельных видов собственности с учетом идей, лежащих в основе учения евразийства, в частности, приоритет духовных ценностей над материальными; переход от начал абсолютной собственности к идее относительной собственности, посредством установления взаимных прав и обязанностей собственников и иных субъектов.

Несмотря на то, что евразийская концепция права собственности была сформулирована в начале 20 века, представляется что она имеет значительный потенциал для преодоления глобальных вызовов, стоящих перед Российской Федерацией в настоящее время. Решение проблем устойчивого развития, справедливого распределения материальных благ в обществе - это лишь некоторые направления, в которых рассмотренная концепция может найти свое применение. По этим причинам творческое наследие евразийцев требует внимательного изучения и переосмысления.

\section{ЛИТЕРАТУРА}

1. Суханов Е.А. Проблемы реформирования вещного права // Закон. 2018. № 12. С. 46 - 52.

2. Карпов Е.А. Конвергенция романо-германской и англосаксонской моделей права собственности в гражданском праве России // Международное публичное и частное право. 2020. № 2. С. 26 - 29.

3. Ткаченко С.В. Правовая модернизация постсоветской России // Юридические исследования. — 2014. - № 5. - С.12-22. D0I: 10.7256/23059699.2014.5.11817. URL: https://e-notabene.ru/lr/article_11817.html

4. Кожокарь И.П. Аксиологические дефекты нормативной подсистемы механизма гражданско-правового регулирования // Власть Закона. 2017. № 3. С. $69-92$ (С. 76).

5. Покровский И.А. Основные проблемы гражданского права. Изд. 3-е, стереотип. М.: «Статут», 2001. - 353 с.

6. Мейер Д.И. Русское гражданское право (в 2 ч.). По исправленному и дополненному 8-му изд., 1902. Изд. 3-е, испр. М.: «Статут», 2003. - 831 с.

7. Суучка П.И. Курс советского гражданского права. Том третий: Особенная часть гражданского права. М.: Государственное социально-экономическое издательство, 1931. - 206 с.

8. Томсинов В.А. Правовая мысль русской послереволюционной эмиграции: «Евразийская» теория государства и права Н.Н. Алексеева // ЗаконодательСтВ0. - 2002. - № 3. - С. 84-88.

9. Алексеев, Н.Н. Собственность и социализм: Опыт обоснования социально-экономической программы евразийства. Париж: Евразийское книгоизд-во, 1928. -87 C. 
10. Алексеев, Н.Н. Собственность и социализм: Опыт обоснования социально-экономической программы евразийства / Русский народ и государство. М., «Аграф», 1998. - 640 c.

11. Шершеневич Г.Ф. Учебник русского гражданского права / Десятое издание. - М.: Издание Бр. Башмаковых, 1912. - VIII, 952 с.

12. Советское гражданское право: Учебник. В 2-х томах. Т. 1/ Илларионова Т.И., Кириллова М.Я., Красавчиков 0.А. и др.: Под ред. 0.А. Красавчикова. -3-е изд., испр. и доп.- М.: Высш. шк., 1985.- 544 с.

13. Гражданское право: учебник: в 4 т. /отв. ред. Е.А. Суханов. Т. 2 : Вещное право. Наследственное право. Интеллектуальные права.

14. Личные неимущественные права. - 2-е изд., перераб. и доп. - Москва: Статут, 2019. - 464 с.

15. Карапетов А.Г. Экономический анализ права. - М.: Статут, 2016. - 528 с.

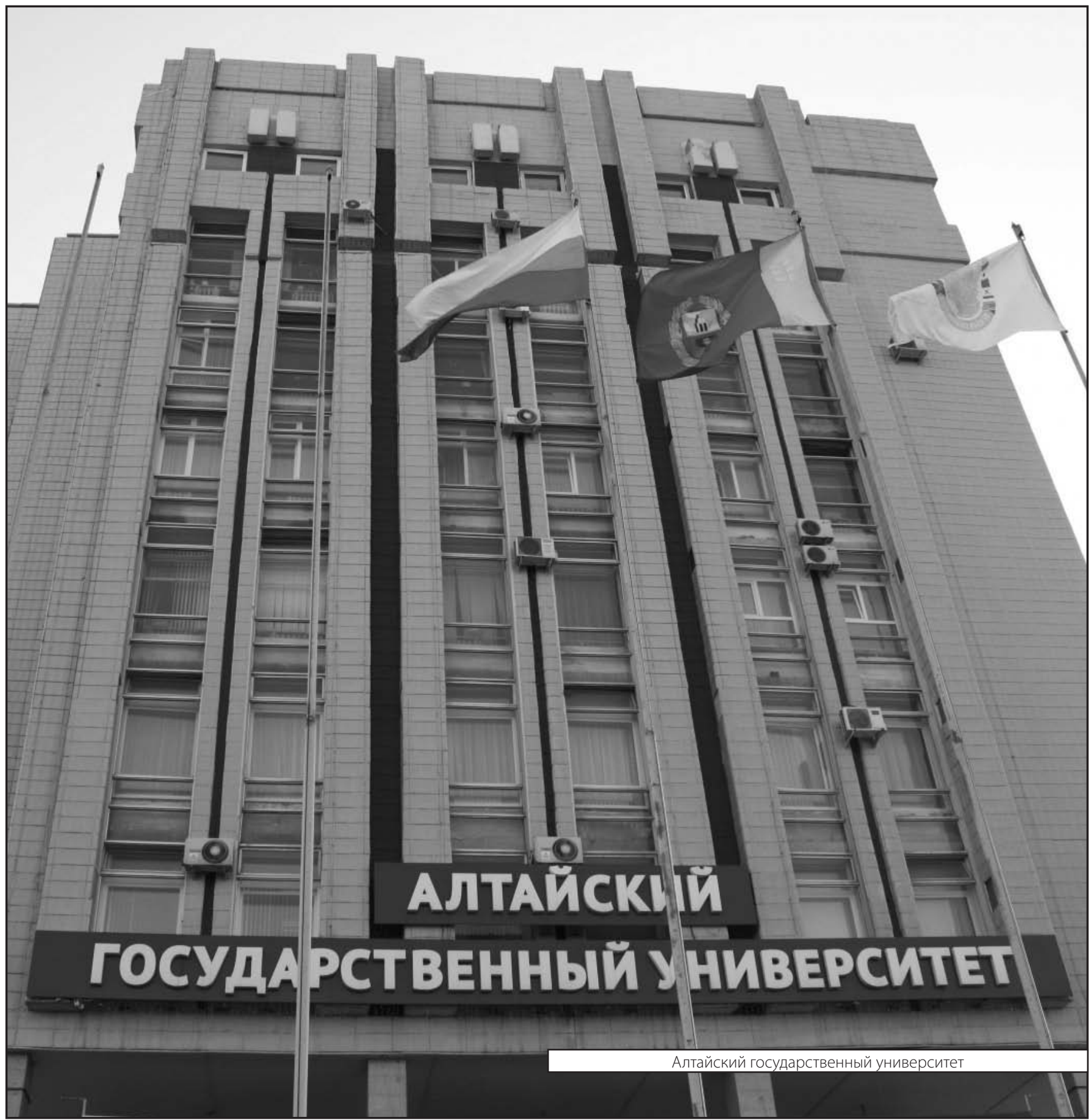

